\title{
Evaluation of the impact of the COVID-19 pandemic on photochemical pollution in urban areas
}

\author{
Farid Rahal $^{1^{(\mathbb{D}}}$, Salima Rezak $^{2}{ }^{\mathbb{D}}$, Noureddine Benabadji $^{(\mathbb{D}}$ \\ ${ }^{1}$ Architecture Department, Laboratory of Sciences, Technology and Process Engineering, University of Sciences and Technology of \\ Oran, Mohamed Boudiaf, BP 1505 El M’Naouer, Oran, Algeria \\ ${ }^{2}$ Architecture Department, Laboratory of Chemistry of Inorganic Materials and Applications, University of Sciences and Technology of \\ Oran, Mohamed Boudiaf, BP 1505 El M’Naouer, Oran, Algeria \\ ${ }^{3}$ Architecture Department, Laboratory of Analysis and Application of Rayonnements, University of Sciences and Technology of Oran, \\ Mohamed Boudiaf, BP 1505 El M’Naouer, Oran, Algeria
}

\begin{abstract}
Background: The effect of confinement due to the coronavirus disease 2019 (COVID-19) pandemic on air pollution has been investigated in several cities. Indeed, the concentration of the main air pollutants have decreased significantly due to the decline in activities consuming fossil fuels. However, it was found that the concentration of ozone $\left(\mathrm{O}_{3}\right)$ has increased in Nice, Rome, Valence, Barcelona, Turin, and Wuhan. The main objective of this study was to assess the impact of the COVID-19 pandemic on photochemical pollution in Oran, Algeria.

Methods: In Oran, a port city in the north-west of Algeria, the level of tropospheric ozone pollution was measured automatically every $15 \mathrm{~min}$ for 10 days at the same location before and after the confinement period, using an electronic nose, called APOMOS (air pollution monitoring system). This electronic circuit is equipped with an electrochemical sensor (MQ131) as well as a temperature and humidity sensor. Sampling was carried out in the central part of the Oran agglomeration from May to June 2020. The data related to the direction and intensity of the wind were processed to find a correlation between these parameters and the concentration of ozone in the studied area.

Results: The impact of confinement on the increase of the ozone pollution levels in Oran, was estimated to be $52 \%$. On the other hand, the statistical study of the pollution levels, the intensity and direction of the wind indicates that the important part of the downtown is involved in the generation of tropospheric ozone.

Conclusion: The confinement due to the COVID-19 pandemic in Oran led to the reduction of the road traffic and pollutants emissions and the increase of ozone levels in urban area. Thus, ozone was less degraded because there were low levels of nitrogen oxides (NOx) in the atmosphere of this city during the confinement period.

Keywords: Tropospheric ozone, Confinement, COVID-19, Electronic nose

Citation: Rahal F, Rezak S, Benabadji N. Evaluation of the impact of the COVID-19 pandemic on photochemical pollution in urban areas. Environmental Health Engineering and Management Journal 2020; 7(4): 237-243. doi: 10.34172/EHEM.2020.28.
\end{abstract}

\author{
Article History: \\ Received: 18 July 2020 \\ Accepted: 21 September 2020 \\ ePublished: 8 November 2020
}

\section{Introduction}

In December 2019, the coronavirus disease 2019 (COVID-19) pandemic appeared in Wuhan, China. Within a few weeks, the disease had spread to countries in all parts of the world (1). Like other countries in the world, Algeria was affected by the COVID-19 pandemic from February 25, 2020 (2). In order to reduce the risk of exposure to the virus, partial confinement measures have been imposed on some cities that had reported the highest number of contaminated cases (3). Confinement is a barrier measure used to break the chain of virus transmission during an epidemic (4). Thus, the epidemiological situation was stabilized by taking a set of measures such as staying off educational establishments and higher, stopping urbansuburban transport and air traffic, closing non-critical businesses, and finally, closing borders $(5,6)$.

Confinement measures have been imposed in several countries in order to control the spread of COVID-19 and to mitigate its impact (7) and to contribute to the flattening of the epidemic curve. At the same time, the confinement of the population, the reduction of public transport and essential economic activities significantly decreased the road traffic, and consequently, reduced the levels of air pollution in Barcelona (8), São Paulo (9), Delhi (10), and 
Salé (11).

However, increased ozone $\left(\mathrm{O}_{3}\right)$ pollution was found in Nice Rome, Turin, Valencia, and Wuhan (12). The same phenomenon was observed in Barcelona (Spain), in which maximum daily 8-hour $\mathrm{O}_{3}$ concentrations increased and it was estimated to be between +33 and $+57 \%$. This phenomenon can be explained by the lower titration of $\mathrm{O}_{3}$ by nitrogen oxide $(\mathrm{NO})$ and a decrease in nitrogen oxides $(\mathrm{NOx})$ in a limited number of volatile organic compounds in the environment $(8,13)$.

However, there is not enough evidences to get a general idea of this phenomenon. In order to have a better understanding, we have carried out a statistical data processing. In this study, the direction and intensity of the wind in relation to the recorded $\mathrm{O}_{3}$ concentrations were also investigated.

\section{Materials and Methods}

Study area

Oran is located in a semi-arid region (14), and is made up of several municipalities with a total population of 1026900 people in 2015 and a traffic flow greater than
$600 \mathrm{PCU} / \mathrm{h}$ (passenger car unit) at the evening peak hour in the main roads of the city (15).

In this second largest city in Algeria, the first case of COVID-19 was reported on March 19, 2020. Figure 1 shows the progression of proven cases from COVID-19 with the confinement stages in Oran. As shown in this figure, the highest number of COVID-19 cases was reported between $3 \mathrm{PM}$ to $7 \mathrm{AM}$.

Ozone measurements were made in Oran, every 15 minutes for 10 days at the same location before and after the confinement period (from May to June 2020). Figure 2 shows the study area and sampling point.

Working day correspond to ordinary economic activities with heavy road traffic and industrial units in production. Saturday is a semi-working day, which corresponds to a drop in economic activities and road traffic. On Friday, which is a public holiday, these two parameters decrease more.

\section{Ozone measurement}

The measurements were taken with an electronic assembly, called APOMOS (air pollution monitoring

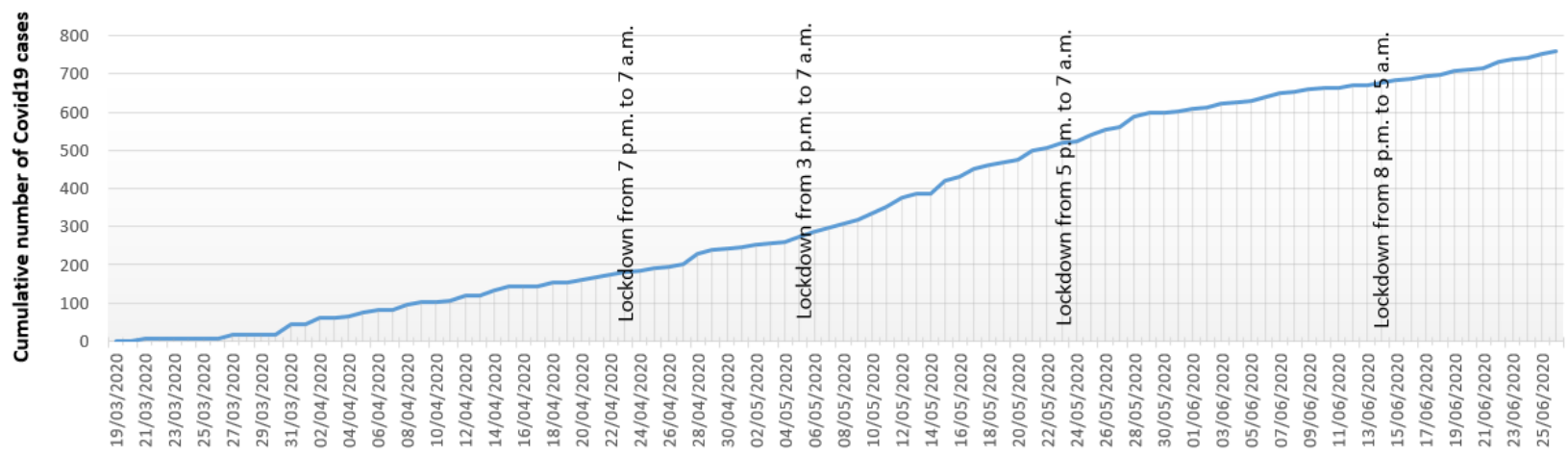

Figure 1. The number of confirmed cases infected with COVID-19 in Oran since 19/03/2020 with the main stages of confinement (6).

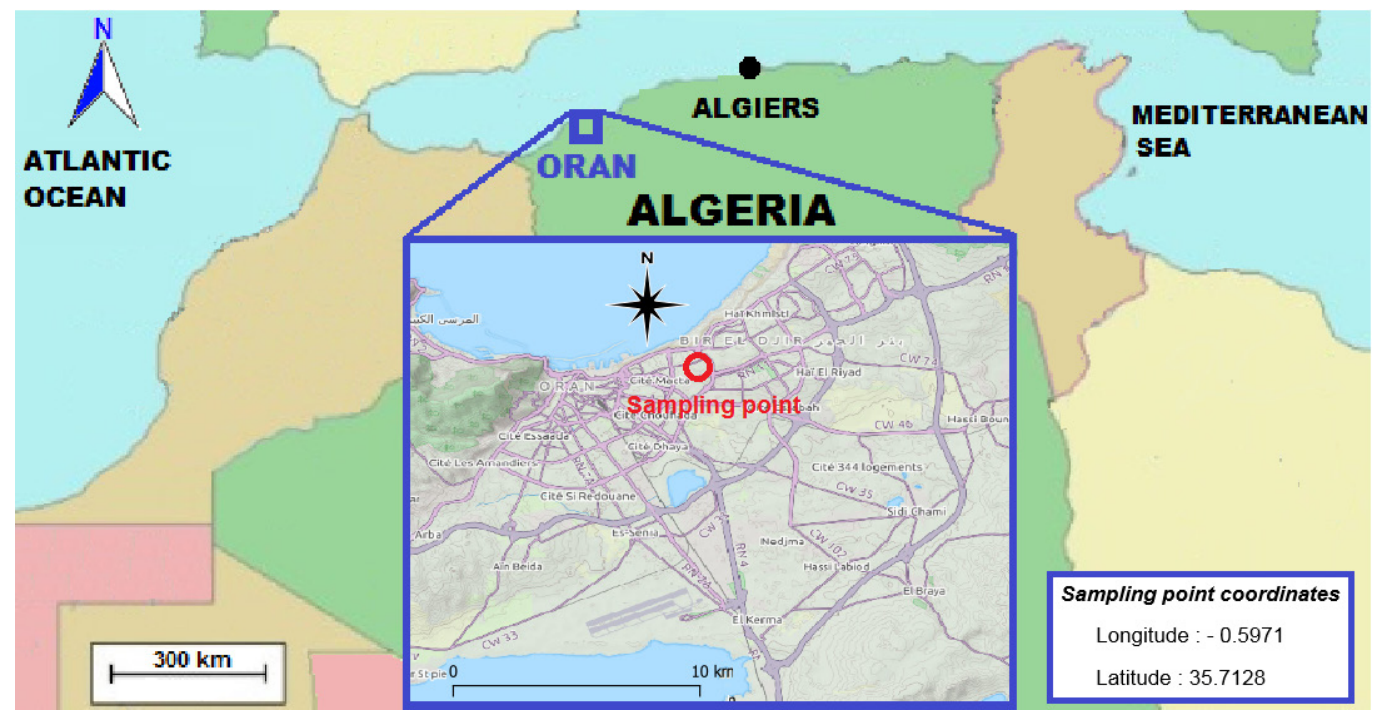

Figure 2. The study area and sampling measurement point. 
system) (Figure 3), which was placed at human height. This system is equipped with two electrochemical sensors (MQ131-Winsen Electronics), one for low concentrations and the other for high concentrations. The detection limits of the sensor range from 10 to $1000 \mathrm{ppb}$. This system is also equipped with a temperature and humidity sensor (DHT22 sensor) for measuring temperature and humidity.

The MQ131 sensor was successfully used in several studies $(16,17)$.

Electrochemical air quality sensors have the potential to fill the gap left by traditional monitoring of air pollution. The cost and size of air pollution sensors is decreasing, which means that it is now possible to use portable and inexpensive air pollution analyzers (18). The APOMOS can manage data acquisition every $15 \mathrm{~min}$.

For a more relevant analysis of the data obtained, it is necessary to process them with statistical tools. Thus, in many applications, the paired data controls other relevant variables through a matching process.

Basic textbooks analyze such data by applying the paired Student's t-test. This test is optimal when the differences are normally distributed (19). However, before using the test, it is necessary to verify that the data follow a normal distribution. Given the size of our data, the Shapiro-Wilk test (20) appears to be the most suitable one for performing a normality test.

\section{Results}

Analysis of the raw data showed an increase in ozone concentrations during confinement (Figure 4). This figure shows the average of the measurements collected during and after confinement for the working day, Friday which is a public holiday, and Saturday which is a semi-holiday in Algeria.

The ozone concentrations increased significantly during confinement except for Saturday morning, in which a very modest increase was observed (Table 1). This can be

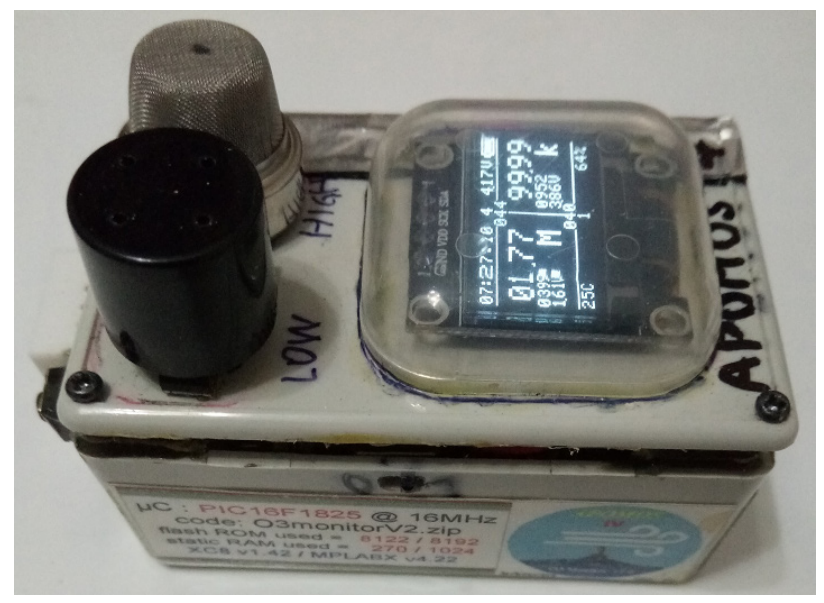

Figure 3. The APOMOS equipped with MQ131 detectors for low and high concentrations, and the DHT22 sensor for measuring temperature and humidity. explained by a significant difference in relative humidity between Saturday mornings during and after confinement.

Indeed, the relative humidity of Saturdays after confinement is $12.61 \%$ higher than that of the same days during confinement according to the data recorded by the DHT22 sensor of APOMOS. Figure 5 shows the average measurements collected every 15 minutes by the APOMOS regarding temperature and humidity for the working day, Friday, and Saturday.

Usually, in a historical data set, the presence of multiple outliers can easily go unnoticed due to the masking effect (21).

Statistical analysis of the data collected makes it possible to detect any atypical or extreme outliers. Figure 6 shows a

Table 1. Relative increase in ozone concentrations during confinement and standard deviation of data during and after confinement

\begin{tabular}{lcc}
\hline Day & $\%$ & SD during confinement \\
\hline Working Day & 76.02 & 25.08 \\
\hline Friday & 78.63 & 45.22 \\
\hline Saturday & 2.13 & 42.13 \\
\hline
\end{tabular}
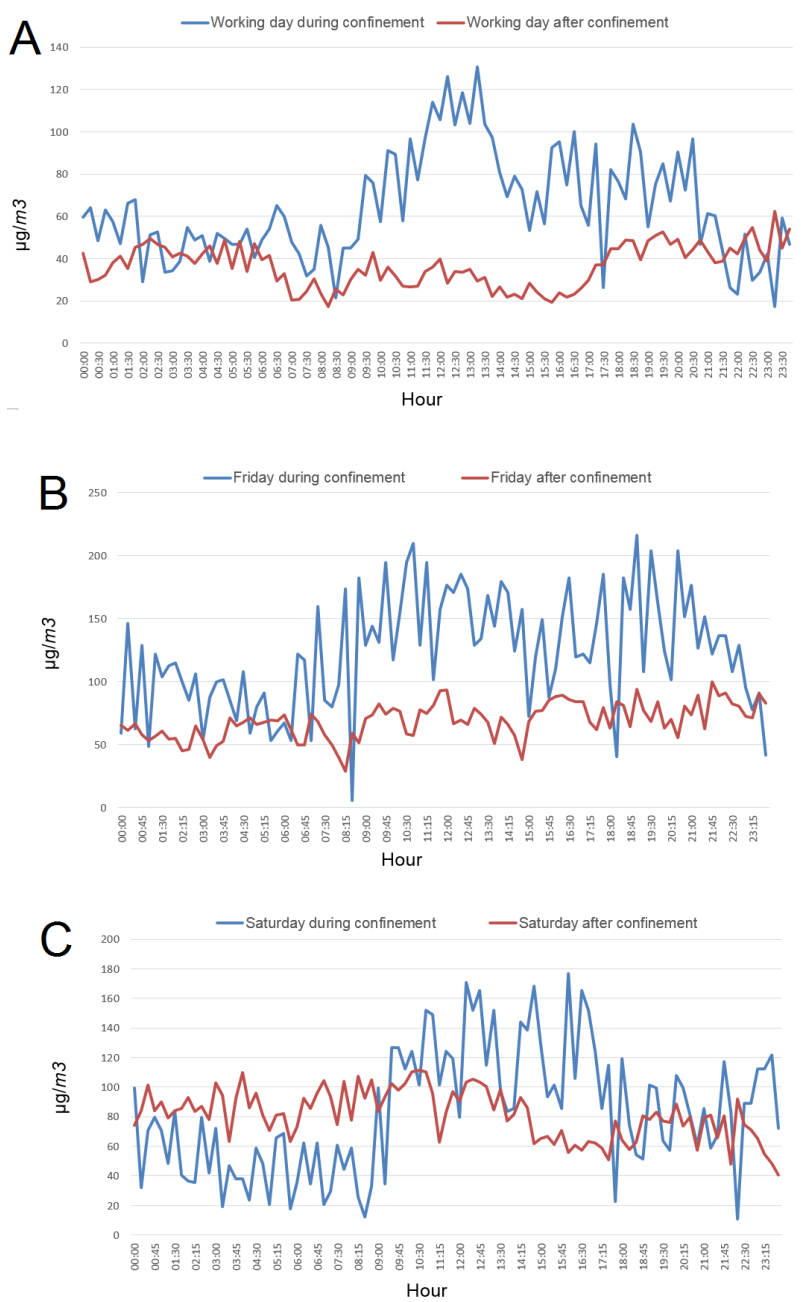

Figure 4. The average of the measurements collected during and after confinement for the working day (A), Friday (B), and Saturday (C). 

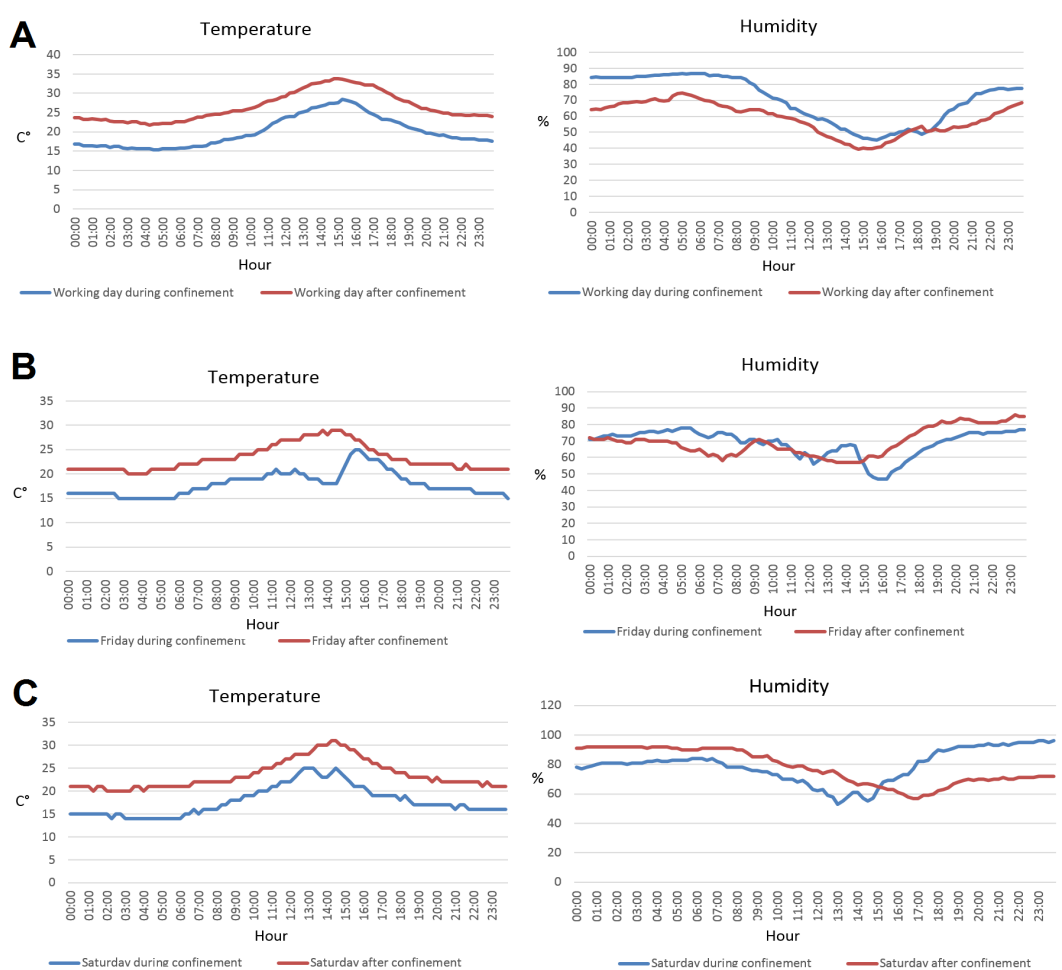

Figure 5. Average measurements collected by the APOMOS regarding temperature and humidity every 15 min during and after confinement for the working day (A), Friday (B), and Saturday (C).

box-and-whisker plot box or box plot of the data recorded during confinement, which indicates the extreme values of the ozone concentrations.

Thus, data processing makes it possible to perform a statistical analysis with the paired student's $t$ test in order to verify the increase of ozone concentrations during and after confinement. The value of pairing is that each individual is their own witness. With this method, we can eliminate the inter-individual variability that risks masking the phenomenon studied (22).

However, the paired student's $t$ test can only be used if the differences between the ozone concentrations during the two periods studied follow a normal distribution.

This condition can be evaluated using the Shapiro-Wilk test, the null hypothesis of which is that the differences follow a normal distribution if $\mathrm{P}$-value is greater than 0 . Table 2 shows the results of the Shapiro-Wilk test applied to the working day, Friday, and Saturday.

According to the results, the paired student's $t$ test can be applied during and after confinement. The results presented in Table 3 clearly indicate that there was a significant increase in the ozone concentrations during the confinement period in Oran.

Several studies have shown the effect of meteorological factors on photochemical pollution (23-25). Thus, to assess the role of meteorology on the concentrations of tropospheric ozone measured in this study, meteorological data were obtained from the meteorological station at EsSenia airport (Longitude: $-0.6^{\circ}$, Latitude: $35.63^{\circ}$ ), which is about $10 \mathrm{~km}$ from the sampling site.

Ground-level ozone concentrations are closely related to wind speed (26) and wind direction (27). Figure 7 produced by the openair package in $\mathrm{R}$ language from Carslaw and Ropkins (28) shows the level of ozone pollution in Oran according to the direction and speed of the wind during and after the COVID-19 confinement.

\section{Discussion}

Like other cities around the world (29), Oran also experienced an increase in the concentrations of groundlevel ozone during the confinement imposed by the

Table 2. The results of the Shapiro-Wilk test applied to evaluate the ozone concentrations in Oran during and after confinement for the working day, Friday, and Saturday.

\begin{tabular}{lcc}
\hline & Shapiro-Wilk test & $\boldsymbol{P}$ value \\
\hline Working day & 0.98726 & 0.4852 \\
\hline Friday & 0.98718 & 0.4802 \\
\hline Saturday & 0.9775 & 0.09764
\end{tabular}

Table 3. The results of the paired Student's t-test applied to evaluate the ozone concentrations in Oran during and after confinement for the working day, Friday, and Saturday.

\begin{tabular}{lccc}
\hline & $\boldsymbol{t}$ & $\boldsymbol{d f}$ & $\boldsymbol{P}$ value \\
\hline Working day & 18.762 & 95 & $<2.2 \times 10^{-16}$ \\
\hline Friday & 23.171 & 94 & $<2.2 \times 10^{-16}$ \\
\hline Saturday & 14.943 & 95 & $<2.2 \times 10^{-16}$ \\
\hline
\end{tabular}

$t$ : $\mathrm{t}$ test statistics; $d f$ : degrees of freedom. 


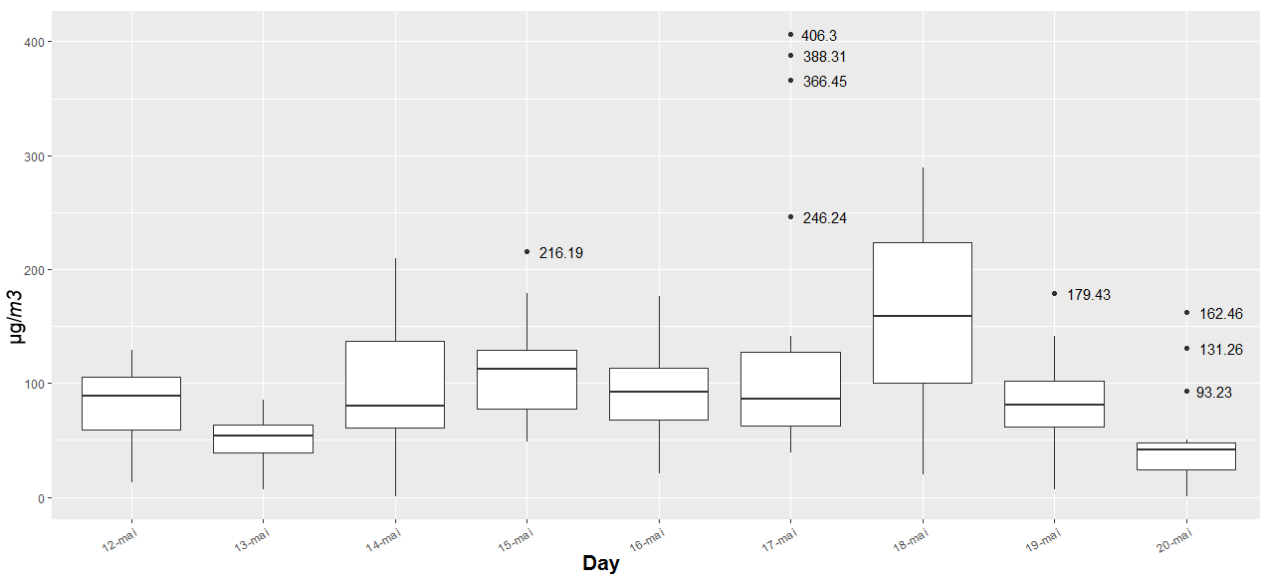

Figure 6. Box plot of some of the values recorded during confinement, showing the extreme values of the ozone concentrations.
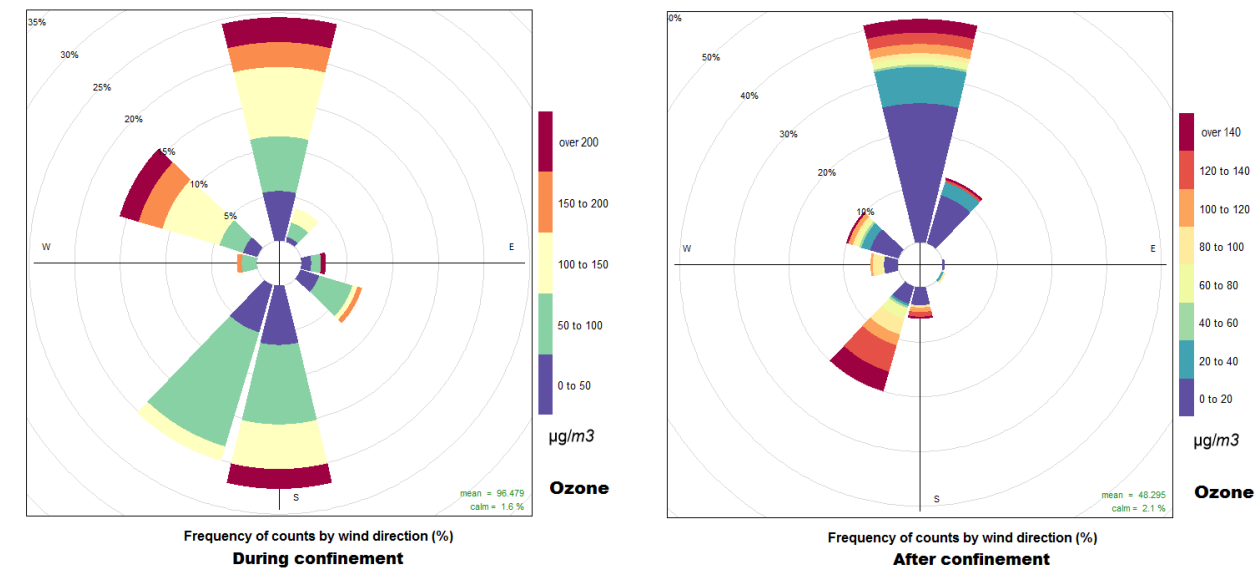

Figure 7. Level of ozone pollution in Oran according to the direction and speed of the wind during and after the COVID-19 confinement.

COVID-19 pandemic. This result is consistent with the results reported by Sicard et al who explained it mainly, by an unprecedented reduction in the NOx emissions in the studied cities (12).

As shown in Figure 4, this increase in Oran is remarkable for working day compared to that for Fridays and Saturdays.

This difference is explained by the fact that working day experiences a higher level of emission of ozone precursor pollutants such as NOx due to heavy road traffic compared to public holidays in Oran (15).

Furthermore, Table 3 confirms this increase from the results of the paired student's $t$ test. It was verified that the data obtained from this test follow a normal distribution, so it can be concluded that this test is the optimum one (30).

This result was obtained thanks to a prior statistical processing of the data by detecting the extreme values as shown in figure 6.

The wind is an important element in the transport of pollutants. The study of the intensity and direction of the wind, during and after the confinement, allowed us to assess the ozone pollution in Oran in function of these parameters, as shown in Figure 7. This approach can be used to identify the origin of the pollution which can be either industrial, residential or resulting from road traffic.

The most intense ozone pollution during confinement follows two main directions. The first one is a north-south direction from the city center to the outskirts. The density of ozone precursors was high in the residential sector in this part of city. The second direction goes from South to North and is explained by the presence of industrial zones located in the south of the city. After the confinement, the North-South direction disappeared, and ozone formed in the city center was degraded by NOx from road traffic.

According to Figures 4 and 5, there is a reverse relationship between ground-level ozone concentrations and levels of relative humidity. Indeed, the ozone level is naturally low when the relative humidity of the air increases, this humidity reduces the air temperature by reducing the chain length of chemical amplifiers with peroxy radicals $\left(\mathrm{HO} 2, \mathrm{RO} 2\right.$, and $\mathrm{RC}(\mathrm{O}) \mathrm{O}_{2}$ ), as well as 
decreasing the length of the $\mathrm{NO}_{2}$ chain and limiting the photochemistry (31).

According to these figures, changes in ozone concentrations follow a pattern similar to changes in temperature. The usual increase in temperature leads to an increase in $\mathrm{O}_{3}$, which was observed in Barcelona (8).

The overall increase in ozone concentration in Oran was $52 \%$, which is higher than that reported in the other cities, as shown in Table 4.

This difference can be explained by the different amounts of sunlight recieved by Oran and European cities. This difference can also be explained by the significant difference between the mean daily maximum temperature in Oran during the confinement which occurred in May and that of the other cities whose confinement period corresponded generally to March 2020.

During the study period, the mean daily maximum temperature in Oran was $23.9^{\circ} \mathrm{C}$ while for the cities of Nice, Rome, Turin Valencia, and Wuhan, it was reported to be $14.9,15.2,13.4,19.3$, and $14.6^{\circ} \mathrm{C}$, respectively (32).

Obviously, humidity, wind speed, wind direction, population density, and ozone-producing sources, influence this phenomenon and deserve further study.

\section{Conclusion}

In May 2020, when a strict confinement imposed by the COVID-19 pandemic, a sharp reduction in the flow of road traffic led to an increase more than $70 \%$ in ozone concentration compared to June 2020 when the confinement was considerably reduced. As it was observed in other cities, this is probably due to the reduction of NOx emissions from road traffic which usually contributes to the degradation of ozone in urban areas. It can be concluded that the COVID-19 pandemic had a significant impact on the increase in ozone pollution in Oran during the confinement period. The use of portable and low-cost sensors made it possible to observe this phenomenon. This increase due to confinement was also shown by the statistical study of the collected data. In addition, the disappearance after confinement of a significant part of the ozone pollution in the north-south direction of the wind indicates the share of the densified downtown residential sector in this type of pollution. As a result, emissions of ozone precursors increased. The strict confinement in Oran resulted in the reduction of NOx emissions from road traffic, and subsequently, resulted in

Table 4. Percentage increase in ozone concentrations during confinement (present study, 12).

\begin{tabular}{lc}
\hline City & Ozone increase (\%) \\
\hline Oran & 52 \\
\hline Nice & 24 \\
\hline Rome & 14 \\
\hline Turin & 27 \\
\hline Valencia & 2.4 \\
\hline Wuhan & 36 \\
\hline
\end{tabular}

the lower ozone titration.

The impact of the COVID-19 pandemic on photochemical pollution in urban settings, which has been measured in Oran and other cities, is confirmed. However, the complexity of the tropospheric ozone formation phenomenon means that there may be remarkable differences between the studied cities.

\section{Acknowledgements}

The authors would like to thank the Algerian Ministry of Health, Population and Hospital Reform, for providing data used in this study. The authors confirm that no funding was received to carry out this study

\section{Ethical issues}

The authors certify that this manuscript is the original work of the authors, all data collected during the study are presented in this manuscript, and no data from the study has been or will be published elsewhere separately.

\section{Competing interests}

The authors declare that they have no competing interests.

\section{Authors' contributions}

All authors contributed to the structure, content, and writing of the paper. All authors read and approved the final manuscript.

\section{References}

1. Fanelli D, Piazza F. Analysis and forecast of COVID-19 spreading in China, Italy and France. Chaos Solitons Fractals 2020; 134: 109761. doi: 10.1016/j.chaos.2020.109761.

2. Hamidouche M. COVID-19 outbreak in Algeria: a mathematical model to predict the incidence. medRxiv 2020. doi: $10.1101 / 2020.03 .20 .20039891$

3. Rahal F, Rezak S, Baba Hamed FZ. Impact of meteorological parameters on the Covid-19 incidence. The case of the city of Oran, Algeria. medRxiv 2020. doi: 10.1101/2020.07.10.20151258.

4. Badsi D, Terki K, Elkebir D, Benali D, Zitouni H, Mazour $\mathrm{F}$, et al. Activités et situation épidémiologiqueConsultation Covid-19 EHU Oran . [cited 2020 Jul 31] Available from: https://www.ehuoran.dz/Actualites/2020/04/ bullletin $\% 20 \mathrm{de} \% 20$ consultation $\% 20$ covid/BULLETIN\%20 D\%27INFORMATION\%20DE\%20LA \%20\%20\%20 CONSULTATION\%20COVID\%20EHUO.pdf. [French].

5. Bulletin d'information covid-19 au CHU Oran. Covid-19 Situation au CHU d'Oran $N^{\circ} 1$. [cited 2020 Jul 31] Available from: https://www.univ-oran1.dz/index.php/bulletin-dinformation-covid-19-au-chu-oran.html. [French].

6. MSPRH. Ministère de la Santé, de la Population et de la Réforme Hospitalière, Algérie. http://covid19.sante.gov.dz/ carte/. 2020.

7. Anderson RM, Heesterbeek H, Klinkenberg D, Hollingsworth TD. How will country-based mitigation measures influence the course of the COVID-19 epidemic? Lancet 2020; 395(10228): 931-4. doi: 10.1016/s01406736(20)30567-5.

8. Tobías A, Carnerero C, Reche C, Massagué J, Via M, 
Minguillón MC, et al. Changes in air quality during the lockdown in Barcelona (Spain) one month into the SARSCoV-2 epidemic. Sci Total Environ 2020; 726: 138540. doi: 10.1016/j.scitotenv.2020.138540.

9. Nakada LYK, Urban RC. COVID-19 pandemic: impacts on the air quality during the partial lockdown in São Paulo state, Brazil. Sci Total Environ 2020; 730: 139087. doi: 10.1016/j.scitotenv.2020.139087.

10. Mahato S, Pal S, Ghosh KG. Effect of lockdown amid COVID-19 pandemic on air quality of the megacity Delhi, India. Sci Total Environ 2020; 730: 139086. doi: 10.1016/j. scitotenv.2020.139086.

11. Otmani A, Benchrif A, Tahri M, Bounakhla M, Chakir EM, El Bouch M, et al. Impact of Covid-19 lockdown on $\mathrm{PM}(10), \mathrm{SO}(2)$ and $\mathrm{NO}(2)$ concentrations in Salé city (Morocco). Sci Total Environ 2020; 735: 139541. doi: 10.1016/j.scitotenv.2020.139541.

12. Sicard P, De Marco A, Agathokleous E, Feng Z, Xu X, Paoletti E, et al. Amplified ozone pollution in cities during the COVID-19 lockdown. Sci Total Environ 2020; 735: 139542. doi: 10.1016/j.scitotenv.2020.139542.

13. Menut L, Bessagnet B, Siour G, Mailler S, Pennel R, Cholakian A. Impact of lockdown measures to combat Covid-19 on air quality over western Europe. Sci Total Environ 2020; 741: 140426. doi: 10.1016/j.scitotenv.2020.140426.

14. Bounoua L, Safia A, Masek J, Peters-Lidard C, Imhoff ML. Impact of urban growth on surface climate: a case study in Oran, Algeria. J Appl Meteorol Climatol 2009; 48(2): 21731. doi: 10.1175/2008jamc2044.1.

15. Rahal F, Hadjou Z, Blond N, Aguejdad R. Croissance urbaine, mobilité et émissions de polluants atmosphériques dans la région d'Oran, Algérie. Cybergeo: European Journal of Geography. OpenEdition 2018; 850. doi: 10.4000/ cybergeo.29111

16. Dam N, Ricketts A, Catlett B, Henriques J. Wearable sensors for analyzing personal exposure to air pollution. 2017 Systems and Information Engineering Design Symposium (SIEDS); 2017 Apr 28; USA: IEEE; 2017. doi: 10.1109/ sieds.2017.7937695.

17. Kim SH, Jeong JM, Hwang MT, Kang CS. Development of an IoT-based atmospheric environment monitoring system. International Conference on Information and Communication Technology Convergence (ICTC) 2017; 861-3. doi: 10.1109/ictc.2017.8190799.

18. Gunawan TS, Munir YM, Kartiwi M, Mansor H. Design and implementation of portable outdoor air quality measurement systemn using arduino. Int J Electr Comput Eng 2018; 8(1): 280-90. doi: 10.11591/ijece.v8i1.pp280-290.

19. Freidlin B, Miao W, Gastwirth JL. On the use of the Shapiro-
Wilk test in two-stage adaptive inference for paired data from moderate to very heavy tailed distributions. Biom J 2003; 45(7): 887-900. doi: 10.1002/bimj.200390056.

20. Shapiro SS, Wilk MB. An analysis of variance test for normality (complete samples). Biometrika 1965; 52(3/4): 591-611. doi: 10.2307/2333709.

21. Vargas NJ. Robust estimation in multivariate control charts for individual observations. J Qual Technol 2003; 35(4): 367-76. doi: 10.1080/00224065.2003.11980234.

22. Camlong-Viot C, Morgant G. Évaluations comparatives: présentation de deux outils statistiques. Immuno-analyse \& Biologie Spécialisée 2005; 20(5): 320-8. doi: 10.1016/j. immbio.2005.05.003. [In French].

23. Xu J, Zhu Y. Some characteristics of ozone concentrations and their relations with meteorological factors in Shanghai. Atmos Environ 1994; 28(20): 3387-92. doi: 10.1016/13522310(94)00154-d.

24. Wang T, Wu YY, Cheung TF, Lam KS. A study of surface ozone and the relation to complex wind flow in Hong Kong. Atmos Environ 2001; 35(18): 3203-15. doi: 10.1016/s13522310(00)00558-6.

25. Zhao W, Gao B, Liu M, Lu Q, Ma SX, Sun JR, et al. [Impact of meteorological factors on the ozone pollution in Hong Kong]. Huan Jing Ke Xue 2019; 40(1): 55-66. doi: 10.13227/j. hjkx.201803151.

26. Tong L, Zhang H, Yu J, He M, Xu N, Zhang J, et al. Characteristics of surface ozone and nitrogen oxides at urban, suburban and rural sites in Ningbo, China. Atmospheric Research 2017; 187: 57-68. doi: 10.1016/j. atmosres.2016.12.006.

27. Li K, Chen L, Ying F, White SJ, Jang C, Wu X, et al. Meteorological and chemical impacts on ozone formation: A case study in Hangzhou, China. Atmos Res 2017; 196: 40-52. doi: 10.1016/j.atmosres.2017.06.003.

28. Carslaw DC, Ropkins K. openair-an R package for air quality data analysis. Environ Model Softw 2012; 27-28: 5261. doi: 10.1016/j.envsoft.2011.09.008.

29. Siciliano B, Dantas G, da Silva CM, Arbilla G. Increased ozone levels during the COVID-19 lockdown: analysis for the city of Rio de Janeiro, Brazil. Sci Total Environ 2020; 737: 139765. doi: 10.1016/j.scitotenv.2020.139765.

30. Lehmann EL. Testing Statistical Hypotheses. 2nd ed. USA: Springer; 1986.

31. Yu S. Fog geoengineering to abate local ozone pollution at ground level by enhancing air moisture. Environ Chem Lett 2019; 17(1): 565-80. doi: 10.1007/s10311-018-0809-5.

32. World Meteorological Organization (WMO). World Weather Information Service. [cited 2020 Jul 17]. Available from: https://worldweather.wmo.int. 